University of Wollongong

Research Online

Faculty of Social Sciences - Papers (Archive) Faculty of Arts, Social Sciences \& Humanities

2001

Offender risk and needs assessment: Some current issues and suggestions

Mitchell K. Byrne

University of Wollongong, mbyrne@uow.edu.au

Stuart Byrne

University of South Australia

Katherine Hillman

University of South Australia

Emma Stanley

University of South Australia

Follow this and additional works at: https://ro.uow.edu.au/sspapers

Part of the Education Commons, and the Social and Behavioral Sciences Commons

Research Online is the open access institutional repository for the University of Wollongong. For further information contact the UOW Library: research-pubs@uow.edu.au 


\title{
Offender risk and needs assessment: Some current issues and suggestions
}

\author{
Abstract \\ Crime impacts upon the community at multiple levels, causing distress and loss for the victims, and \\ feelings of insecurity for the public, as well as adding to the drain on financial resources for governments. \\ This makes the accurate identification of risk of reoffending and the determination of efficacious \\ rehabilitation strategies imperative. Key principles in cognitive and behavioural psychology can contribute \\ to this task. This paper will review the issue of risk assessment and describe the applicability of \\ functional analysis to forensic psychology. Two studies by the authors will be used to illustrate concepts \\ raised in this review. The paper will conclude with a model that may help guide the realistic \\ implementation of detailed individual functional analyses of offenders' behaviour.

\section{Keywords} \\ issues, current, suggestions, assessment, offender, needs, risk \\ Disciplines \\ Education | Social and Behavioral Sciences

\section{Publication Details} \\ Byrne, M. K., Byrne, S., Hillman, K. \& Stanley, E. (2001). Offender risk and needs assessment: Some current \\ issues and suggestions. Behaviour Change, 18 (1), 18-27.
}




\title{
Offender Risk and Needs Assessment: Some Current Issues and Suggestions
}

\author{
Mitchell K. Byrne \\ University of Wollongong \\ Stuart Byrne, Katherine Hillman, and Emma Stanley \\ University of South Australio
}

\begin{abstract}
Crime impacts upon the community at multiple levels, causing distress and loss for the victims, and feelings of insecurity for the public, as well as adding to the drain on financial resources for governments. This makes the accurate identification of risk of reoffending and the determination of efficacious rehabilitation strategies imperative. Key principles in cognitive and behavioural psychology can contribute to this task. This paper will review the issue of risk assessment and describe the applicability of functional analysis to forensic psychology. Two studies by the authors will be used to illustrate concepts raised in this review. The paper will conclude with a model that may help guide the realistic implementation of detailed individual functional analyses of offenders' behaviour.
\end{abstract}

Forensic psychology has undergone somewhat of a renaissance over the last decade. This follows a lengthy period in the wilderness during the "nothing works" period of the 70 s and $80 \mathrm{~s}$. The nothing works belief was fuelled by Martinson (1974), who reviewed 231 studies of the outcomes of treatment programs for offenders between the years of 1945 to 1967 . His conclusion that correctional rehabilitation is ineffective became the dominant mindset amongst administrators, professionals, and the public. This perception persisted from the mid-70s through to the early $90 \mathrm{~s}$.

The appeal of Martinson's conclusions was ubiquitous. Left-wing crime theorists attributed the cause of crime to inequities in society while right-wing protagonists saw support for their retribution-orientated approach to offenders. The systemic outcome of the broad acceptance of Martinson's conclusions was that little or no effort was put into the development of rehabilitation programs, and forensic psychology lagged behind other psychologies, especially clinical psychology, in the development of effective treatment strategies.

While clinical psychologists developed a formulation-based approach to problem analysis and treatment design, forensic psychologists were limited by theories of crime that attributed responsibility for offending behaviour to sociological, biological, and/or nondeterminist causes. This effectively hamstrung the application of scientific principles to the process of changing individual offending behaviour.

The change in this nothing works mentality was initiated by Thornton (1987), who re-examined the papers reviewed by Martinson using a more methodologically sound set of criteria. For each of the 231 studies he asked three questions:

- Was recidivism used as an outcome measure?

An earlier version of this paper was presented at the 22 nd Annual Conference of the Australian Association for Cognitive and Behaviour Therapy in Perth, Western Australia, July 1999.

Address for correspondence: Mitchell K. Byrne, Department of Psychology, University of Wollongong,

Northfields Avenue, Wollongong NSW 2522, Australia. Email: mbyrne@uow.edu.au 
- Were subjects randomly allocated to treai. ment/control conditions, or were treatment and control subjects matched?

- Was the methodology of the study sound?

Only 34 of the 231 studies met these criteria. Of these, 1 study demonstrated a worse outcome for the treatment group, 17 studies showed no difference between groups, and 16 (47\%) demonstrated significant advantage following treatment.

Since Thomton's re-examination of the data, other research has demonstrated treatment efficacy of forensic rehabilitation. In a recent paper, McGuire (1998) reported that meta-analytic studies of offender rehabilitation provide evidence of an effect on recidivism, ranging from $10 \%$ to $36 \%$. McGuire noted that effect sizes such as these were only marginally less than those obtained for psychological interventions into mental health problems, that they were comparable to that of AZT in the treatment of AIDS, and that they were greater than that of Aspirin or bypass surgery for the prevention of myocardial infarction. The implication is that research and effort into forensic rehabilitation, given the broad impact of crime on the community, may lay claim to resources comparable to those expended elsewhere.

\section{Enhancing Treatment Efficacy}

To achieve the effect sizes quoted by McGuire (1998), a number of key features of successful interventions have been identified. Hollin has summarised the core components of successful programs in six key statements, as follows (Hollin, 1999, cited in Howells et al., 2000):

1. Indiscriminate targeting of treatment programs is counterproductive in reducing recidivism; medium- to high-risk offenders should be selected and programs should focus on criminogenic targets.

2. The type of treatment program is important, with stronger evidence for structured behavioural and multimodal approaches than for less focused approaches.

3. The most successful studies, while behavioural in nature, include a cognitive component to focus on attitudes and beliefs.
4. Treatment programs should be designed to engage high levels of offender responsivity.

5. Treatment programs conducted in the community have a stronger effect than residential programs. While residential programs can be effective, they should be linked structurally with communitybased interventions.

6. The most effective programs have high treatment integrity in that they are carried out by trained staff, and the treatment initiators are involved in all the operational phases of the treatment programs.

\section{Risk and Needs}

This paper focuses on the first of Hollin's statements: the targeting and focus of programs. Specifically, it reflects the risk (of reoffending) presented by an offender and the identified (criminogenic) needs of that offender that should be targeted in order to ameliorate such a risk. Risk is conventionally construed as "stable" or nonchangeable aspects of an individual that have been statistically associated with a high likelihood of recidivism. Examples of such variables include age at first offence and current age of the offender. Needs are in fact risk variables that are "dynamic" or changeable. Often referred to as criminogenic needs (Howells, Watt, Hall, \& Baldwin, 1997), these dynamic risk variables include skills deficits, current behaviours, personality dispositions, attitudes, cognitions, beliefs, and general life circumstances.

Risk has been the subject of significant research and the development of actuarial measures of risk has occurred both in Australia (Cumberland \& Boyle, 1997; Ward \& Dockerill, 1999) and abroad (Hart, 1998; Monahan \& Steadman, 1994; Prins, 1996; Steadman et al., 1994; Webster, Eaves, Douglas, \& Wintrup, 1995; Webster, Harris, Rice, Cormier, \& Quinsey, 1994). Research such as this has equipped forensic psychologists to identify high-risk offenders based on their past behaviours and other static (nonchangeable) variables.

Dynamic risk factors have also been the subject of considerable research, with a number of measures being developed to assess an off-ender's 
level of criminogenic need. For example, Hemphill, Hare, and Wong (1998) assessed the predictive utility of a personality dimension, "psychopathy", using the Hare Psychopathy Checklist (Hare, 1991). They found that psychopaths were three times more likely to recidivate and four times more likely to violently recidivate than nonpsychopaths. Further-more, Hemphill and colleagues (1998) found that the PCL - $\mathbf{R}$ scores were more strongly correlated with recidivism than many standard risk scales constructed specifically for that purpose.

A range of dynamic or needs-based risk scales are used widely by criminal justice agencies. Some, such as the Violent Risk Appraisal Guide (VRAG; Rice \& Harris, 1995) and Rapid Risk Assessment for Sex Offence Recidivism (RRASOR; Hanson, 1997) focus on particular categories of offending. Others provide a more general overview of propensity to reoffend, being somewhat ubiquitous across offence categories. Of these more general dynamic risk measures, the Level of Service Inventory (Andrews, 1982) has been presented as amongst the more reliable of measures (Andrews \& Bonta, 1995; Gendreau, Goggin, \& Paparozzi, 1996).

The sophistication of risk measurement has recently been enhanced by the delineation of two classes of dynamic risk variables: stable dynamic and acute dynamic factors (Hanson \& Harris, 1998, 2000). Acute dynamic risk factors refer to those aspects of the individual offender that are observed to be immediately antecedent to reoffending. Useful for monitoring risk during community supervision, acute dynamic risk factors might include negative mood or alcohol intoxication. Stable dynamic factors, which Hanson and Harris (1998) identify as most strongly identifying recidivists, include personality disorders and deviant attitudes. This is consistent with the observations of Zamble and Quinsey (1997), who have identified "dynamic antisociality" as most predictive of violent recidivism in mentally disordered offenders.

\section{Functional Analysis of Offending Behaviour}

With the range of risk variables thus far identified, a comprehensive process of risk assessment appears unclear. However, one strategy incorporating both actuarial and clinical measures that has the potential to identify static, stable dynamic, and acute dynamic risk variables is functional analysis. We undertake a functional analysis to determine why a behaviour occurs. A clear and simple description of functional analysis has been provided by Tustin (1993) who suggests that "(a) functional analysis involves a process of identifying possible functions of a response by gathering objective information about the environmental events immediately surrounding it, especially the antecedents and consequences of the response" (p. 39).

Howells (1998) has detailed the process of applying functional analyses to offending behaviour by proposing 12 variables that should be included in offender needs assessment, an example of which is applied to aggressive behaviour in Table 1. This approach is multimodal, involving both environmental and intrapersonal factors, and examines both operant and antecedent factors in the establishment and maintenance of offending behaviour. Howells (1998) also emphasises the need to assess contextual factors in the development of the offending behaviour, and in doing so extends the import of triggering events from immediate triggers to the behaviour to the general environmental context in which the proximal trigger occurred.

However, it is not possible to undertake a detailed individual functional analysis with each offender. In practice, correctional service agencies tend to apply general knowledge of the relationship between certain offender variables and offending behaviour to identify those who pose the greatest risk to the community, then target scarce resources at those individuals. This is achieved essentially by using conventional, primarily static, measures of risk assessment. The exploitation of new insights into offender risk assessment is a developing process, and scarce services may potentially 


\section{TABLE 1}

Variables to Include in a Functional Analysis of Aggression and Violence

Frequency, intensity, and form (of current and previous violent behaviour)

Environmental triggers (including background stressors)

Cognitive antecedents (including biases in appraisal of events, dysfunctional schemata, and underlying beliefs and values supporting aggression)

Affective antecedents (emotions preceding aggressive acts, e.g., anger or fear)

Physiological antecedents

Coping problem-solving skills

Personality dispositions (e.g., anger-proneness, impulsivity, psychopathy, general criminality, overcontrol, undercontrol)

Mental disorder variables (mood, brain impairment, delusions, hallucinations, personality disorders)

Consequence/functions of aggressive acts

(for the perpetrator and others, short term and long term; including emotional consequences such as remorse and peer group or institutional reinforcement)

Buffer factors (good relationships, family support, achievement in some area)

Opportunity factors (weapons, victim availability, restrictions)

Disinhibitors (alcohol, drugs)

Note. From "Cognitive behavioural therapy for anger, aggression and violence", by K. Howells, 1998, in N. Tarrier (Ed.), Cognitive behavioural therapy for complex cases (pp. 295-318), Chichester: Wiley. Copyright 1998 by Tarrier. Adapted with author's permission.

be wasted through the absence of dynamic risk assessment and screening.

In the rest of this paper, we will describe two studies that explore strategies for the inclusion of dynamic independent variables into the conventional assessment processes used by a majority of Australian correctional service providers. This inclusion, which aimed to minimise disruption to day-to-day staff activity, is evaluated for its potential contribution to the determination of reoffence risk. This research was undertaken by the University of South Australia in cooperation with the South Australian
Department of Correctional Services (DCS). It was designed as a pilot study from which the DCS might draw inferences, and as such employed a limited data set. The focus is on violent behaviour because of the greater impact of such offences and the low base rate, which effects statistical risk prediction.

\section{Study 1}

In the first study (Stanley, 1998) it was our intention to examine the current risk assessment used by the DCS and explore the idea that it may be enhanced by the inclusion of a simple measure of the personality of the offender, thus tapping into more (stable) dynamic aspects of risk. Of 250 male community corrections clients invited to participate, 36 agreed to be involved. The sample included only clients with "new" offences who had yet to receive an assessment of risk.

Community corrections staff in several states in Australia currently rely on an adapted version of the Wisconsin Risk-Need Assessment Scale (WRAS; Baird, 1981) to determine offender risk and needs. The WRAS is a clinical interview-based assessment which is used primarily to assess risk and determine the appropriate level of supervision for each client. The focus of the WRAS is on the assessment of static risk factors. While it also identifies some dynamic risk/need factors, these are used primarily to inform level of supervision, and not as targets for change or indices of program efficacy.

Various studies have supported the use of the WRAS in a community correctional setting (National Institute of Corrections, 1981; Payne, McCabe, \& Walker, 1974). Gendreau, Goggin, and Little's (1996) meta-analysis reported that the WRAS was not significantly better or worse than other composite scales. The main difficulty with the WRAS lies in its reliance on static variables in predicting risk. Static variables, by definition, do not change over time, and as such, the level of risk as measured by the WRAS rarely changes. Thus, whilst it may be an acceptable instrument for measuring risk, an assessment based solely on the WRAS is unlikely to offer guidance 
as to program determination or treatment outcome. Whilst the WRAS does measure some dynamic factors, there have been very few studies that report on their predictive validity (Bonta, 1996). Furthermore, in many jurisdictions (including South Australia), the WRAS has been adapted and modified to suit local needs, without adequate evaluation of the efficacy of either the original form or the adapted version.

The stable dynamic variable of offender personality has been previously identified as most informative when assessing recidivism (Hanson \& Harris, 1998; Zamble \& Quinsey, 1997). One such measure is the Carlson Psychological Survey (CPS, Carlson, 1981, 1982). The CPS is a psychometric instrument that was developed to investigate dimensions of psychopathology of persons who come to the attention of criminal justice systems. It is a selfreport scale that contains four clinical scales: chemical abuse, antisocial tendencies, self-depreciation, and thought disturbance. It was designed specifically for use with forensic populations, and the wording for items has been drawn directly from prisoner dialogue.

There is some evidence to suggest that the CPS is an accurate measure of risk, incorporating both stable and acute dynamic variables. Carlson (1982) has reported a significant relationship between the antisocial tendencies (stable) scale and recidivism. Black (1993) found that repeat incarcerates had a statistically significant higher score on antisocial tendencies compared with first-time incarcerates. He also found that these scores correlated closely to static risk factors such as frequency of previous offending. The CPS has been shown to assist in the prediction of behaviour disorder/violence (antisocial tendencies - stable), mental health vulnerability (thought disturbance - acute), suicidality (self-depreciation acute/stable), and chemical dependency (chemical abuse - acute) (Black, 1993; Byrne, 1993; Carlson, 1982). It has been used by mental health professionals to screen for psychopathology on dimensions relevant to offenders. The CPS is primarily a measure of dynamic variables, so it offers the potential for a better assessment of offender need and for linking need to program delivery. The CPS has the added advantage of being useful in measuring treatment effects (via pre/post treatment measurements), and could thus be used to link risk and need to intervention outcomes.

In this study, we administered both the WRAS and the CPS to the sample. The results were limited by the sample size but, as a pilot study, it did provide an indication of possible data trends. The most important statistic that emerged was from a comparison between CPS subscale Antisocial Tendencies and the WRAS item Assaultive Offence. As a rule, past behaviour predicts future behaviour. Assaultive Offence should relate to offenders' assessed personality characteristics derived from Antisocial Tendencies. Furthermore, both past violence and characteristics of antisocial personality disorder have considerable support in the literature as predictors of future recidivism (Howells et al., 2000). However, there was no significant relationship between the CPS subscale Antisocial Tendencies and the WRAS item Assaultive Offence in this study $(r=.068$, $p=0.69$ ). We interpreted the lack of a relationship as indicating the different aspects of risk/need measured by the two instruments: static in the case of the WRAS Assaultive Offence item and (stable) dynamic in the case of the CPS Antisocial Tendencies item.

We hypothesised that some of the offenders had changed in terms of their propensity to offend, and that the CPS reflected this change.

\section{Study 2}

The second study (Hillman, 1998), which was also exploratory in nature, examined this change potential further, as it relates specifically to violent offending. In this study, we examined two instruments used to assess for the potential to be violent: the Violent Offender Treatment Program Risk Assessment Scale (VOTP RAS; Howells et al., 1997) and the Violence Potential Index (VPI) of the Personality Assessment Inventory (PAI; Morey, 1991; Morey \& Henry, 1994). The VOTP RAS targets primarily static or contextual variables, while the VPI is a measure of (primarily stable) dynamic risk variables. 
This study was a case analysis involving some retrospective factors (as scored by the VOTP RAS) and some current factors (as measured by the PAI). Participants were 57 violent male offenders (as defined by the Justice Administration National Classification of Offences; JANCO), of whom 23 were parolees and 34 current prisoners.

The VOTP RAS was designed to screen offenders for inclusion in violence prevention programs (Hall, 1998). It was modified by Ward (1997), and this version was used in the current study. Ward reported that the VOTP RAS has achieved between $72 \%$ and $76 \%$ accuracy in identifying violent recidivism, comparing favourably with the Statistical Information on Recidivism Scale (SIR), which achieved $65 \%$ accuracy in predicting violent recidivism (Bonta, Harman, Hann, \& Cormier, 1996). The false positive rate for the VOTP RAS has been reported as $13.9 \%$, compared with rates reported in the literature of $26 \%$ to $67.9 \%$ (Ward, 1997). In the interests of $\cdots$ ucing false negatives, the current study a. sted a cutoff score lower than that us is by Ward. Only a marginal increase in false positives resulted (16.3\%).

The VOTP RAS is scored using casenote (archival) information, and as such requires no direct interaction with the offender. The scale is divided into two sections: level of harm caused by violent offences and probability of future harm. The probability measure is derived from information about number of past offences, age at onset of offending behaviour, and alcohol and other drug misuse.

The PAI is a self-administered inventory of some 344 questions. It has non-overlapping scales measuring clinical, interpersonal, and treatment constructs as well as four validity scales. Items from within the various scales were drawn to develop the VPI, which Morey and Henry (1994) suggested will assess the likelihood of an individuals future violent behaviour. The VPI consists of 20 items drawn from scales relating to aggression, antisocial personality, borderline personality, mania, paranoia, schizophrenia, and substance abuse. For example, from the Schizophrenia scale, items are drawn from the subscales relating to psychotic thoughts and social detachment, but not from the items relating to thought disorder. The VPI has correlated highly with the Minnesota Multiphasic Personality Inventory scales of psychoticism $(r=.65)$ and hostility $(r=.63)$, as well as the self-report version of the Hare Psychopathy Checklist $(r=.67)$ (Morey, 1991).

By obtaining a score for each participant on both measures, this study explored the contention that the VOTP RAS (static) and the VPI (dynamic), measure different aspects of risk and therefore may inform different approaches to treatment. Spearman correlation coefficients

TABLE 2

VOTP RAS and VPI Coefficients

\begin{tabular}{llllllll}
\hline & AGG-P & AGG & ANT-A & ANT-S & VPI & PVO & MSO \\
\hline AGG & $.945^{* *}$ & & & & & & \\
ANT-A & $.597^{* *}$ & $.620^{* *}$ & & & & & \\
ANT-S & $.530^{* *}$ & $.534^{* *}$ & $.598^{* *}$ & & & & \\
VPI & $.703^{* *}$ & $.643^{* *}$ & $.655^{* *}$ & $.671^{* *}$ & & & \\
PVO & .021 & .096 & .189 & .188 & 0.40 & & \\
MSO & .082 & .157 & -.095 & -.109 & -.112 & $.513^{* *}$ & \\
VOTP RAS & .198 & .259 & .186 & .116 & .119 & $.573^{* *}$ & $.524^{* *}$
\end{tabular}

Note. AGG-P = physical aggression. $A G G=$ aggression. ANT-A = antisocial behaviours. ANT- $\mathrm{S}=$ stimulus seeking . $\mathrm{PVO}=$ past violent offence. $\mathrm{MSO}=$ most serious offence.

$* p<.05$, two-tailed. ${ }^{* *} p<.001$, two-tailed. 


\section{TABLE 3}

Rotated Factor Analysis - Varimax.

\begin{tabular}{|c|c|c|c|}
\hline \multirow[b]{2}{*}{1} & \multicolumn{2}{|l|}{ Factor } & \multirow[b]{2}{*}{ Variable } \\
\hline & 2 & 3 & \\
\hline .855 & & & Poor emotional control, feelings of betrayal, impulsivity (BOR) \\
\hline .836 & & & Suspiciousness, belief that treated unfairly (PAR) \\
\hline .774 & & & Delusional beliefs, social isolation, and discomfort (SCZ) \\
\hline .588 & & & Lack of empathy, egocentrism, and instability (ANT) \\
\hline .585 & & & Overinvolvement in a variety of activities, inflated self-esteem (MAN) \\
\hline .537 & & & Characteristics and attitudes related to anger, hostility, and aggression (AGG) \\
\hline & .858 & & Past non-violent Offences \\
\hline & .758 & & Age at 1 st offence \\
\hline & .627 & & Alcohol problems \\
\hline & .529 & & Drug problems \\
\hline & & .866 & Most serious offence \\
\hline & & .845 & Past violent offences \\
\hline
\end{tabular}

were computed between the total VOTP RAS and the two subscales most highly related to past violence: most serious offence and past violent offences. The total VPI score and the associated violence scores of physical aggression, aggression, antisocial behaviours, and stimulus seeking were included, and the results are contained in Table 2.

The data presented in Table 2 suggest that the VPI factors that aim to predict future violence are not related to those of the VOTP RAS. That is, the VPI and the VOTP RAS did not measure violence potential or aggression in the same manner.

To explore the data further, a factor analysis using principle components analysis with a varimax rotation was applied to a "composite" test formed by combining the two assessments. Table 3 describes the factors obtained after varimax rotation. From the table, it can be seen that three factors emerge with Eigenvalues greater than one.

Factor 1 includes variables relating to poor mental health and to antisocial and aggressive tendencies. This factor represents the dynamic and changeable predictor variables. Past vio- lence did not load on this factor. Factor 1 was labelled Future Risk.

Factor 2 primarily included past nonviolent offences,age at onset of offending, and substance abuse. Factor 2 was labelled as Past Delinquency.

The third factor was also static in nature and encompassed the most serious offence, past violence and aggression. We refer to this factor as Past Violence.

The results suggest that the VOTP RAS and the VPI measure different aspects of potential to reoffend, which might best be described as a potential toward violence (static variables) and triggers for violence (dynamic variables). Static variable assessments, such as the VOTP RAS, ignore the potential for change in the offender's risk profile. A focus on offenders' criminal past and exclusion of factors such as personality characteristics and support networks will result in certain offenders being consistently labelled violent even if their most recent crimes, and indeed their future crimes, are not violent. The results of this study added weight to a distinction between static and dynamic variables and are consistent with the views of Andrews and his colleagues, 
who suggest that the potential to reoffend is assessed differently by the two types of variables (Andrews, 1996; Andrews \& Hoge, 1995; Andrews et al., 1990). This means that an adequate assessment of risk would need to include measures of background factors as well as criminogenic needs in some form of composite test.

\section{Conclusions and Recommendations}

The risk literature has focused on two key forms of risk assessment: clinical and actuarial. Actuarial assessments have received significant support in recent times, and research has delineated three types of variables incorporated in such studies: static, stable dynamic, and acute dynamic. This study, in accordance with others cited, advocates the incorporation of dynamic variables in the prediction of future risk, and suggests that the inclusion of such variables may assist in targeting rehabilitation resources. While the studies reported in this paper were limited by small sample sizes, they do suggsst that standard correctional practice could bo enhanced by the inclusion relevant (dynamic variable) assessments. However, it is our view that the best way of obtaining useful information about an offender's potential to reoffend is to undertake a functional analysis of his offending behaviour, incorporating the risk variables identified in past research as part of this process.

Such an application cognitive-behavioural principles, which we have referred to as criminogenic needs assessment, is not without precedent. Melton, Petrila, Poythress, and Slobogin (1997) referred to the "anamnestic" approach, which "depends on the identification of factors that have distinguished a particular subject's prior displays of aggressive behavior" (p. 284). The problem for the practitioner is the time required to undertake such a process with each offender, making such an approach unrealistic for most practitioners.

A possible solution would be the development of a composite measure that may enable a screening process to be established. The best screening tool would involve a two-step process, beginning with the static variables (to establish a background for an offence) and progressing to the dynamic variables (to establish a current likelihood the offence). The information generated by such an approach would enable a classification of offenders into four groups, as outlined in Figure 1. In this matrix model of offender classification, resources would be directed to those offenders occupying Cells 1 and 2, with a thorough functional analysis determining the intervention required. Resources would be deflected from Cell 4, while successes would be acknowledged, and celebrated, in Cell 3.

Given an accurate identification of those offenders likely to reoffend, and a thorough functional analysis of why they offend, over time more and more offenders would find their way into Cell 3.

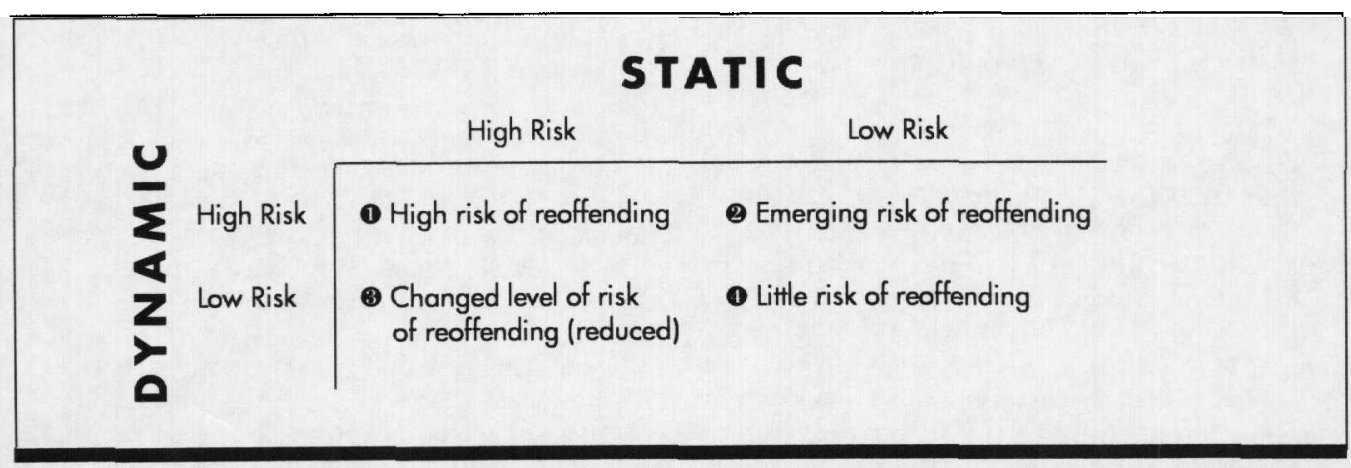

FIGURE 1

Matrix Model of Offender Classification 


\section{References}

Andrews, D.A. (1982). The Level of Supervision Inventory (LSI). Toronto: Ontario Ministry of Correctional Services.

Andrews, D.A. (1996). Criminal recidivism is predictable and can be influenced: An update. Ottawa, Canada: Carleton University, Department of Psychology.

Andrews, D.A., \& Bonta, J. (1995). The Level of Service Inventory-Revised. Toronto: Multi-Health Systems.

Andrews, D.A., \& Hoge, R.D. (1995). The psychology of criminal conduct and principles of effective prevention and rehabilitation. Forum on Corrections Research, 7, www.esc-scc.gc.ca.

Andrews, D.A., Zinger, I., Hoge, R.D., Bonta, J., Gendreau, P., \& Cullen, F.T. (1990). Does correctional treatment work? A psychologically informed meta-analysis. Criminology, 28, 369-404.

Baird, C.S. (1981). Probation and parole classification: The Wisconsin model. Corrections Today, 43 , 36-41.

Black, Q.C. (1993). A review of behaviour disorder and the use of the Carlson Psychological Survey (CPS) as a diagnostic screening instrument in the forensic setting. Thesis submitted for the degree of Master of Applied Psychology, University of Adelaide, Australia.

Bonta, J. (1996). Risk-needs assessment and treatment. In A. Harland (Ed.), Choosing correctional options that work: Defining the demand and evaluating the supply (pp. 18-32). Thousand Oaks, CA: Sage.

Bonta, J. (1997). Predicting adult offender recidivism. Ottawa: Department of the Solicitor General of Canada.

Bonta, J., \& Cormier, R.B. (1999). Corrections research in Canada: Impressive programs and promising prospects. Canadian Journal of Criminology, 41 , $235-247$

Bonta, J., Harman, W.G., Hann, R.G., \& Cormier, R.B. (1996). The prediction of recidivism among federally sentenced offenders: A re-validation of the SIR scalc. Canadian Journal of Criminology, 38, 61-79.

Byrne, M. (1993). Predicting behaviour disorder and reducing recidivism: A follow up to the $E$ Division Planning Group (Report). South Australia: Department of Correctional Services.

Carlson, K.A. (1981). A modern personality test for offenders: The Carlson Psychological Survey. Criminal Justice and Behaviour, 8, 185-200.

Carlson, K.A. (1982). Carlson Psychological Survey manual. Michigan: Sigma Assessment Systems.

Cumberland, A.K., \& Boyle, G.J. (1997). Psychometric prediction of recidivism: Utility of the Risk Needs Inventory. Australian and New Zealand Journal of Criminology, 30, 72-86.
Gendreau, P., Goggin, C., \& Little, T. (1996). Predicting adult offender recidivism: What works! (Use Report No. 1996-07). Ottawa: Department of the Solicitor General of Canada.

Gendreau, P., Goggin, C., \& Paparozzi, M. (1996). Principles of effective assessment for community corrections. Federal Probation, 60, 64-70.

Hall, G. (1998). The violent offender treatment program: Practice and issues. Paper presented at the 18 th Annual Congress of the Australian and New Zealand Association of Psychiatry, Psychology and Law, Melbourne, Australia.

Hanson, R.K. (1997). The development of a brief actuarial risk scale for sexual offence recidivism (User Report No. 1997-04). Ottawa: Department of the Solicitor General of Canada.

Hanson, R.K., \& Harris, A.J.R. (1998). Dynamic predictors of sexual recidivism (User Report No. 1998-01). Ottawa: Department of the Solicitor General of Canada.

Hanson, R.K., \& Harris, A.J.R. (2000). The Sex Offender Need Assessment Rating (SONAR): A method for measuring change in risk levels (User report). Ottawa: Department of the Solicitor General of Canada.

Hare, R.D. (1991). The Revised Psychopathy Checklist. Toronto: Multi-Health Systems.

Hart, S.D. (1998). The role of psychopathy in assessing risk for violence: Conceptual and methodological issues. Legal and Criminological Psychology, 3, 121-137.

Hemphill, J.F., Hare, R.D., \& Wong, S. (1998). Psychopathy and recidivism: A review. Legal and Criminological Psychology, 3, 139-170.

Hillman, K.J. (1998). Predicting violent recidivism: Examining static and dynamic predictors using the Violent Offender Treatment Program Risk Assessment Scale (VOTP RAS) and the Personality Assessment Inventory (PAI). Unpublished honours thesis, University of South Australia.

Howells, K. (1998). Cognitive behavioural therapy for anger, aggression and violence. In N. Tarricr (Ed.), Cognitive behavioural therapy for complex cases (pp. 295-318). Chichester: Wiley.

Howells, K., Day, A., Byrne, M.K., White, L.J., Hart, K., $\&$ Nakos, J. (2000). Best practice literature reviews: Rehabilitative strategies for preventing re-offending (Vol. 1). Adelaide: University of South Australia.

Howells, K., Watt, B., Hall, G., \& Baldwin, S. (1997). Developing programmes for violent offenders. Legal and Criminological Psychology, 2, 117-128.

Martinson, R. (1974). What works? Questions and answers about prison reform. The Public Interest, 35, 22-54.

McGuire, J. (1998). Alternatives to custodial sentences: Effectiveness and potential for development (Memorandum of Evidence to the Home Affairs Committee). United Kingdom: House of Commons. 
Melton, G.B., Petrila, J., Poythress, N.G., \& Slobogin, C. (1997). Psychological evaluations for the courts (2nd ed.). New York: Guilford.

Monahan, J., \& Steadman, H.J. (Eds). (1994). Violence and mental disorder: Developments in risk assessment. Chicago: Chicago University Press.

Morey, L.C. (1991). The Personality Assessment Inventory: Professional manual. Florida: Psychological Assessment Resources.

Morey, L.C., \& Henry, W. (1994). Personality Assessment Inventory. In M.E. Maruish (Ed, The use of psychological testing for treatment planning and outcome assessment (pp. 185-216). New Jersey: Lawrence Erlbaum.

National Institute of Corrections. (1981). The Model Probation and Parole Management Program. Washington, DC: Author.

Payne, C., McCabe, S., \& Walker, N. (1974). Predicting offender-patients' reconvictions. British Journal of Psychiatry, 125, 60-64.

Prins, J. (1996). Risk assessment and management in criminal justice and psychiatry. Journal of Forensic Psychiatry, 7, 42-62.

Rice, M.E., \& Harris, G.T. (1995). Violent recidivism: Assessing predictive validity. Journal of Consulting and Clinical Psychology, 63, 737-748.

Stanley, E. (1998). The comparison and utility of two risk assessment forms for offenders at a correctional centre. Unpublished honours thesis, University of South Australia.

Steadman, H.J., Monahan, J., Appelbaum, P.S., Grisso, T., Mulvey, E.P., Roth, L.H., Robbins, P.C., \& Klassen, D. (1994). Designing a new generation of risk assessment research. In J. Monahan \& H.J. Steadman (Eds.), Violence and mental disorder: Developments in risk assessment. Chicago: Chicago University Press.

Thomton, D. (1987). Treatment effects on recidivism: A reappraisal of the "nothing works" doctrine. In B.J. McGurk, D.M. Thornton, \& M. Williams (Eds.), Applying psychology to imprisonment: Theory and practice (pp. 191-217). London: HMSO.

Tustin, R.D. (1993). Functional analysis of challenging behaviours of two people with intellectual disability. Behaviour Change, 10(1), 39-46.

Ward, A. (1997). The predictive accuracy of the Violent Offender Treatment Program Risk Assessment Scale. Unpublished honours thesis, Edith Cowan University, Westem Australia.

Ward, A., \& Dockerill, J. (1999). The predictive accuracy of the Violent Offender Treatment Program Risk Assessment Scale. Criminal Justice and Behaviour, 26(1), 125-140.

Webster, C.D., Harris, G.T., Rice, M.E., Cormier, C., \& Quinsey, V.L. (1994). The Violence Prediction Scheme: Assessing dangerousness in high risk men. Toronto: University of Toronto, Centre for Criminology.

Webster, C.D., Eaves, D., Douglas, K., \& Wintrup, A. (1995). The HCR-20 scheme: The assessment of dangerousness and risk. Vancouver Canada: Simon Fraser University.

Zamble, E., \& Quinsey, V.L. (1997). The criminal recidivism process. Cambridge: Cambridge University Press. 